\title{
Health and hard time
}

$\mathrm{T}$ here are those who argue that the best thing to do with prisoners is to simply lock them up and throw away the key. If their health suffers for it, so be it.

Others contend that as wards of the state, prisoners are entitled to quality health care, for legal, ethical, social and particularly, public health reasons. As part of that, some jurisdictions offer progressive and innovative prison programs, such as one in Brazil, that aim to promote health and civic responsibility by offering inmates reduced sentences in exchange for riding stationary bicycles that generate power to light a boardwalk, or ones in the United States and Japan that involve inmates in the training of guide dogs for the blind.

But what exactly are the legal and ethical obligations to provide health for prisoners? And how does Canada measure up?

Those are tricky questions, experts say.

One thing they do appear to agree on, though, is that the moment the cell door swings shut, the nature of the health care experience changes dramatically. Not only do the risks of contracting an infectious disease, or being violently beaten or sexually abused, increase from the moment someone is warehoused in prison, it's also a whole different world of health care delivery. For those incarcerated in federal prisons, the odds of being quickly seen by a physician, in comparison with Canadians who aren't behind bars, are substantially reduced.

The variation in care is in part the product of the fact that responsibility for health care is no longer vested with a province, but rather, with the Correctional Service of Canada (CSC), notes Howard Sapers, Canada's Correctional Investigator.

But the mere act of incarcerating someone creates certain obstacles in providing health care, he adds. "Penitentiaries are often located in remote parts of the country and it's a challenge

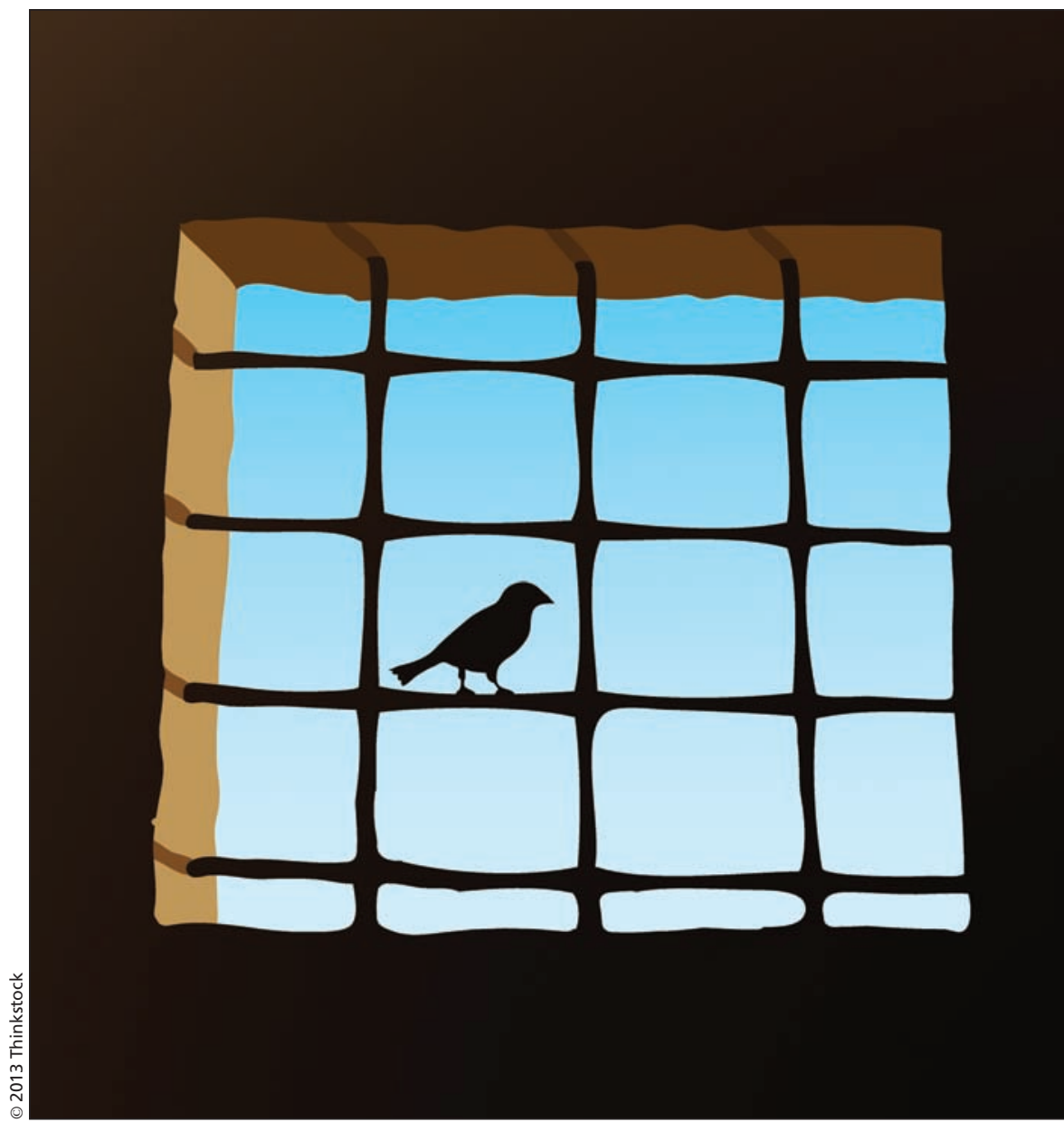

Many say that prisoners must essentially give up hope of receiving quality health care while behind bars.

to recruit and retain health care professionals to work in those settings. It's also a challenge to ensure access for more complex care, because there is always a security element to providing health care to offenders, whether it be inside the penitentiary or when they are removed to outside hospitals."

Certainly staffing is a major challenge. As of December 2012, there were a total of 914 nurses, 312 psychologists, 64 social workers, 27 pharmacists, 17 occupational therapists and only 6 physicians and psychiatrists toiling in Canada's 57 federal prisons. In addition, about 50 additional physicians were providing contract health services to federal prisons.
As of November 2012, those health care practitioners were providing health care to an inmate population of 15055 . Prisoners serving sentences of two years less a day do their time in provincial jails, and their health needs fall under the rubric of provincial and territorial jurisdiction. According to Statistics Canada, there were 24461 inmates in provincial jails in 2011.

History, studies and what statistics are currently available, all indicate that the health risks associated with incarceration are horrid.

Inmates experience rates of HIV 7 to 10 times higher than the general public and rates of hepatitis $\mathrm{C}$ virus are 30 times higher "as a result of their 
history of high-risk behaviours," Sara Parkes, a spokesperson for CSC, writes in an email.

"Hepatitis C, tuberculosis, HIV any of these blood borne communicable diseases tend to promulgate in high density areas and prisons are becoming increasingly high density," says Catherine Latimer, executive director of the John Howard Society of Canada, an advocacy group for rehabilitation, prison reform and other criminal justice issues. "It does have a very negative effect. ... It's because the services don't tend to increase at the same rate as the prison population does so their medical units will only have a certain number of beds in them and the number of health care professionals may not go up as much as the number of inmates that are coming into the system."

Although critics all but scoff at the notion and the federal government has quietly established a task force to examine discrepancies and deficiencies in the provision of health care to inmates, CSC insists that services provided to the incarcerated are consistent and equivalent in all 57 federal prisons.

"CSC provides all inmates in CSC's custody with essential health care, and reasonable access to nonessential mental health care that will contribute to the inmate's rehabilitation and successful reintegration into the community," Parkes says.

Within 24 hours of incarceration, inmates meet with a nurse to identify preexisting health conditions and complete an infectious disease assessment in which they are screened for tuberculosis, hepatitis, HIV and other forms of sexually transmitted disease, Parkes adds. Within two weeks, the newly-incarcerated undergo mental health screening.

And primary care is available round the clock, CSC adds.

Not in the current reality, counters Kim Pate, executive director of the
Canadian Association of Elizabeth Fry Societies, an advocacy group for female prisoners. "They used to work on a 24-hour basis but haven't for a number of years - more than a decade."

Sapers confirms that. "In many institutions across the country, you do not have 24 hour a day, seven day a week staffing of nurses. Often the first responder to a medical emergency is a correctional officer, who may or may not have up to date first aid training and they're the ones that determine whether or not a nurse is called in or whether an ambulance is called."

The variations in care from institution to institution are believed to be a function of the somewhat haphazard way in which the delivery of health care is organized. Essentially, the bulk of health services are contracted from local authorities, which leads to differences in the quality of care in federal prisons, often depending upon the province in which a prison is located.

Sapers says the task of negotiating with 13 different provincial and territorial jurisdictions for access to care is tricky and time-consuming, as well as highly problematic because the health care must be provided while ensuring that security concerns are met.

These and other issues will be the subject of a forthcoming CMAJ series on the provision of health care in federal prisons. Among the topics to be explored:

- Responsibility for care: What legal and ethical obligations, or international laws, compel the provision of health care to prisoners? At what level should that care be provided?

- Fragmentation: Are there varying levels of care in federal prisons? Is there a need to implement national standards?

- Primary care: Who are the first responders to medical emergencies inside Canadian prisons? What train- ing do they receive and how often are their skills re-evaluated? Do prisoners have access to round-the-clock care? Do health care practitioners make less money in prisons?

- Mental health: Have the nation's prisons been transformed into the nation's psychiatric facilities, as the Correctional Investigator of Canada asserts?

- Quality of care: What are the difficulties in delivering care to inmates? How do factors such as security and confidentiality affect the nature of care delivered in prisons? Who decides when to take a prisoner to a hospital or off-site health facility?

- Geriatrics: What is it like to age in prisons? What's the prevalence rate of Alzheimer disease and other forms of dementia? What are the protocols for treatment of such patients? Are elderly patients at a higher risk of violence, sexual assault or other forms of abuse?

- Prescribing patterns: Are concerns about either over- and underprescribing drugs in prisons valid? Are inmates being drugged into submission? Are inmates denied access to some drugs and therapies simply by virtue of being incarcerated?

- Prisoner rights: What is the complaint system? With often little to do but examine case law, are prisoners becoming experts in pressing their complaints? Does incarceration somehow create an entitlement culture?

- Other issues: Is the substance abuse problem within prisons even vaguely under control? How pervasive is the problem of violence? As sentencing laws pack more sardines into the Canadian canners, what is the anticipated impact of overcrowding? Adam Miller, CMAJ

CMAJ 2013. DOI:10.1503/cmaj.109-4389 